\title{
A CRITIQUE OF CARCERAL FEMINIST ARGUMENTS ON RAPE MYTHS AND SEXUAL SCRIPTS
}

\author{
David Gurnham*
}

Given the seriousness for both women and men of misunderstanding or miscategorising sexual victimization and coercion, scholarly engagement with this topic must be self-critical and careful about its methods and conclusions. This article seeks to test the plausibility and justifiability of some key claims made within feminist scholarship as regards the implications of the traditional sexual script and the prevalence and impact of the "real rape" myth. The criticisms offered below with respect to these claims identify three problems: (a) that evidence that would challenge carceral feminists' framing of the traditional sexual script as essentially a blueprint for rape is either marginalized or excluded from consideration altogether; (b) that within that framing the scripted roles of the coercive male and the passive female who is victimized have been allowed to solidify into immovable and immutable stereotypes; (c) that studies purporting to show that rape myth acceptance is highly prevalent and influential on popular attitudes are flawed in ways hitherto not fully acknowledged or explored.

Keywords: rape myths, sexual scripts, carceral feminism, victimization

\section{INTRODUCTION}

Given the seriousness for both women and men of misunderstanding or miscategorizing sexual victimization and coercion, scholarly engagement

* David Gurnham is Associate Professor of Law at the University of Southampton, UK. With the usual caveats, the author would like to thank Ummni Khan, Harry Annison, Imogen Jones, Erika Rackley, and Helen Reece for comments and feedback on previous drafts of this article.

New Criminal Law Review, Vol. 19, Number 2, pps I4I-I70. ISSN 1933-4I92, electronic ISSN 1933-4206. (C) 2016 by the Regents of the University of California. All rights reserved. Please direct all requests for permission to photocopy or reproduce article content through the University of California Press's Reprints and Permissions web page, http://www.ucpress.edu/ journals.php? $\mathrm{p}=$ reprints. DOI: IO.I525/nclr.2OI6.I9.2.I4I. 
with this topic must be self-critical and careful about its methods and conclusions. This article seeks to test the plausibility and justifiability of some key claims made within feminist scholarship as regards the implications of the traditional sexual script and the prevalence and impact of the "real rape" myth. The particular strain of feminist thought focused on here is sometimes known (at least by its detractors) as "carceral," since it represents a view that more criminal convictions of men signifies an advancement for gender justice. Carceral feminism has been criticized already for variously fetishizing female victimization and disempowerment, disingenuously denying its own influence on legal policy, and ignoring the harmful effects of using the violence of state coercion as a means of promoting women's interests. ${ }^{1}$ However, the criticisms offered below focus on three specific problems with that tradition and its claims about sex and rape: (a) evidence that would challenge a carceral feminist framing of the traditional sexual script as essentially a blueprint for rape is either marginalized or excluded from consideration altogether; (b) within that framing the scripted roles of the coercive male and the passive female who is victimized have been allowed to solidify into immovable and immutable stereotypes; (c) studies purporting to show that rape myth acceptance is highly prevalent and influential on popular attitudes are flawed in ways hitherto not fully acknowledged or explored. All three of these problems relate to claims that carry serious implications for criminal law, justice, and policy and as such warrant careful scrutiny.

This critique will proceed by placing relevant feminist arguments alongside empirical research on sexual consent-giving behaviors, as well as by scrutinizing methods and analyses by which those arguments are made out. What this research indicates is that, notwithstanding the manifest problems inherent in the traditional sexual script and its enactment, nevertheless non-victimizing, non-coercive sex can and does occur in a variety of ways that deserve to be recognized as such despite being so scripted, even in the absence of unambiguous and direct agreement between sexual partners. In the first section of this article, therefore, it is argued that we must be wary of the carceral feminist tendency to frame traditional sexual script enactment as essentially and necessarily coercive and victimizing. It may indeed be right to say that by building in a necessary assumption of victimization in

I. For further critical commentary on "carceral" feminism, see Khan (20I4) and Halley (2008). 
situations involving, say, sex that is not positively desired for its own sake, involving an actively pursuing and possibly forceful male and a passive woman, or a woman engaged in sex whilst intoxicated, we will catch more men who have committed rape and sexual assault. It is also true that women may themselves be unwilling or unable to acknowledge that they have been victimized by coercive or manipulative male strategies (Peterson \& Muehlenhard, 2007; Littleton, 20II; Coy, Thiara, \& Kelly, 20II; Turchik, Probst, Irvin, Chau, \& Gidyez, 20Io; Krahé, Bieneck, \& ScheinbergerOlwig, 2007; Busby, 20I2; Gotell, 2012). However, there is a danger that building such assumptions into our thinking also implicitly relies on the same principle that makes rape myth acceptance so odious: in judging a particular incident, we rely not on information as to what actually happened but on a generalized set of beliefs as to what usually happens.

Associated with the carceral feminist orthodoxy regarding the traditional sexual script is the similarly orthodox explanation for attrition rates in rape cases: that in the popular mindset, real rape typically conforms to a stereotype involving violence, an outdoors location, and a pathological stranger, which is qualitatively distinct from what rape much more commonly looks like: committed by an acquaintance, friend, partner, or former partner, and may not involve extrinsic violence, injury, torn clothes, obvious signs of trauma, or prompt reporting; and that even if counter-stereotypical rape is itself still visible despite this false belief, jurors' attentions and attitudes are nevertheless sufficiently drawn by it to become confused and reluctant to convict in the more common scenario (Ellison \& Munro, 20IO; Temkin, 20Io). ${ }^{2}$ The second part of this article critiques this analysis, and in particular suggests that the research involving rape scripts and mock juries that purports to demonstrate both the prevalence and influence of the real rape myth on popular perceptions is flawed in some important respects.

\section{Contextualizing the Question: What this article is about and what it is not about}

Given the fraught political climate associated with the themes and arguments under consideration here, it may be helpful at this point to offer

2. Burton (2013) reports on how police may be influenced by these sorts of factors in handling and categorizing rape complaints; Anderson (2010, p. 65I) reports on research in the United States indicating that "most rape victims do not suffer the kind of genital trauma that hospital staffs can detect." 
a very brief explanation of the article's scope and positioning, and of what lies outside of those parameters. Firstly, why a "critique" of feminist arguments when these may represent the best hope for critically rethinking entrenched gender norms? This article does not position itself as a call to legal actors and decision-makers of criminal justice to disregard feminist insights as such. Being concerned about sexual victimization, violence, coercion, and the like does not commit us to any specific approach to these matters; rather, it commits us to being self-critical about the theory we use in our approach. Critiquing specific feminist studies and arguments (as this article does) is not a betrayal of victims or complainants, nor does it undermine feminist scholarship. This article does not seek to marginalize legitimate concerns about script adherence, nor does it call into question the seriousness or the actuality of female sexual victimization. What it does do by contrast is raise questions about how victimization is framed within a particular (albeit currently highly influential) feminist tradition, and the extent to which this framing can be refined or rethought in capturing the complexity of the relevant issues. After all, if we are serious about understanding and tackling actual instances of coercion and victimization, we cannot afford to become too comfortable in our preferred scholarly structures, no matter how well they accord with our political or moral worldview.

Although the scholarship critiqued here might all be categorized broadly as feminist inasmuch as it seeks to bring to light particular risks, harms, and disadvantages for women, my aim is not to oppose feminist scholarship, nor even to critique feminism as such. There is too much diversity and disagreement within feminist research for that in any case. As I have said, the particular target of my criticisms is a strain of feminism that, as Khan (20I4, p. 265) puts it, "allies itself with a criminalizing state that purports to address systemic and social problems through punishment," and on the subject of sexual offending therefore regards increasing the numbers of convictions for rape and sexual assault a primary aim. In focusing on this particular intellectual strain, it is not my intention to deny that there are many others, and indeed I have been influenced by feminisms that seek to challenge criminal justice solutions (Cossman, 20II; Khan, 20I4).

A final point to make here concerns the legal and theoretical content of this article. The discussion below of the scripts, myths, and stereotypes with regard to consent and culpability takes a broadly legal perspective, but without delving into the specifics of any particular jurisdiction, legislation, or case law. Although of course the concepts debated have particular 
doctrinal, evidential, and philosophical dimensions, this article will not venture into detail on these matters. Therefore, important questions about legal and philosophical definitions of consent and a defendant's mistaken belief in consent, ${ }^{3}$ or about the inclusion or exclusion of evidence in a trial regarding a complainant's past sexual history, are beyond the scope of the article. ${ }^{4}$ Where terms such as "the accused" and "the complainant" are used, this limitation should be borne in mind. Furthermore, although the term "rape" is most often used in this article to refer to the relevant type of wrongdoing, this is not to exclude from consideration sexual assaults that do not involve penile penetration, nor to exclude jurisdictions such as Canada that do not recognize rape as a distinct legal category.

This article begins, then, by plotting out the cultural contours of the so-called traditional sexual script and the demonstrated ambivalence of consent cues for individuals who enact this script in their sexual lives. It then moves on to outlining and critiquing the ways in which that script is mischaracterized in carceral feminist scholarship as essentially a blueprint for male sexual violence against women. The article considers how this leads to gender stereotypes actually being reinforced by feminist analysis and to questionable claims about the prevalence and influence of the real rape myth.

\section{THE TRADITIONAL SEXUAL SCRIPT IN THEORY AND PRACTICE}

In thinking about how to form a critical perspective on discourses of victimization, we start with the view that it is important to listen to what individuals actually say about their own experiences. This is certainly not to deny that in many cases there may be reasons for doubting the ability or willingness of individuals themselves to recognize that they are either a perpetrator or victim of sexually coercive behaviors. We know that individuals' sexual behaviors and attitudes are typically scripted according to sociocultural

3. In Canada, the Criminal Code (R.S.C., I985, c. C-46) s. 273.2 stipulates that the accused cannot rely on his belief in the complainant's consent unless he took "reasonable steps" to ascertain it. In England and Wales, Sexual Offences Act 2003s. I(2) requires the accused to "reasonably believe" that the complainant was consenting.

4. See Jones (2012) on the first point, and Tadros (2006) and Dsouza (2013) on the second. 
norms, and so it would be naïve to assume that apparent choices are always straightforwardly and authentically free and unconstrained (Littleton, 20II; Coy et al., 20II; Turchik et al., 20I0; Krahé et al., 2007). This section acknowledges the importance of feminist arguments that the traditional sexual script and sex role enactment provides a blueprint for behavior that may well be coercive and victimizing. But at the same time, it argues that it is not without significance that traditionally scripted sexual norms are in many cases actually experienced as non-coercive and non-victimizing, and in seeking to distinguish between appropriately criminal and noncriminal sexual behavior, these experiences are instructive.

\section{A. Theorizing the Traditional Sexual Script}

The traditional sexual script casts men in the role of initiators of sex: singleminded and mechanical in their pursuit of sexual satisfaction, and ready to say and do whatever it takes to get it and thereby bolster their manly selfidentity. Women are by contrast cast in the role of gatekeepers of sex and hence also of men's and society's sexual morals: less driven by the need for sexual satisfaction and more attuned to a sense of vulnerability-to pregnancy and to social disapproval consequent upon allowing men free reign to pursue their pleasure (Chapleau \& Oswald, 20I3).

The available empirical research on sexual behaviors and attitudes attests to a widespread belief that this order of things continues to be normal, normative, and natural by both men and women-albeit also challenged by individuals who for various reasons feel able to escape its bonds-and that it accurately describes the way many people actually conduct and reflect upon their sexual lives. Identities may not be quite as simplistically dualistic as active male sexual subjects on the one hand and passive female sexual objects on the other, but the research indicates a continuing relevance of this paradigm. A generation ago, LaPlante, McCormick, and Brannigan (1980) found that men were expected to and many did use a very wide range of methods to overcome women's resistance, whereas women in turn were expected to and did use every means available to avoid or at least delay sex. This finding has more recently been repeated both in terms of beliefs commonly held by men and women, and in sexual practises and attitudes reported (Sakaluk, Todd, Milhausen, \& Lachowsky, 2013).

What the literature suggests is that there has been (and continues to be) a strong acceptance and reaffirmation of a script for heterosexual norms 
amongst both men and women, and that this informs what many people understand to constitute the meaning-giving context for consensual sexual relations (Jozkowski \& Peterson, 2013; Sakaluk et al., 2013; Masters, Casey, Wells, \& Morrison, 2013). But since consent-giving according to the traditional script presupposes a more passive role for women, with the consequent implication that males may feel that their scripted role entitles them to use deceptive or coercive means, feminist critical engagements with this topic have often depicted a good deal of traditionally scripted sexual activity as so limiting of female agency as to render consent invalid or at the very least severely compromised. ${ }^{5}$ Studies informed by a feminist framing script such as those of Beckett et al. (2013), Coy, Kelly, Elvines, Garner, and Kanyeredzi (2013), and Berelowitz, Firmin, Edwards, and Gulyurtlu (2012) take issue with at least three implications of the traditional script. Firstly, sexual acts that a woman agrees to only, for example, to keep the peace in a difficult or potentially abusive relationship or to gain something else (say money, drugs, recognition, or affection) may be classified in liberal theory and law as consensual, since it is open to a jury to find this amounts to making a valid choice. ${ }^{6}$ Secondly, if an incident involves sexual activity that may have been wanted up to a certain point but not actually consented to (say, due to a woman's incapacity at a crucial time), then a rape prosecution may also fail on the grounds of a lack of mens rea on the accused's part (see Peterson \& Muehlenhard, 2007). ${ }^{7}$ Thirdly, where a woman consents to sexual activity $X$ (say, vaginal sex), which the male partner assumes to constitute tacit consent to sexual activity $Y$ (say, anal sex), sexual attitudes research suggests that some people who affirm the traditional sexual script may not recognize any wrongdoing (Jozkowski \& Peterson, 2013).

5. See, e.g., Beckett et al. (2013) and Berelowitz et al. (2012) on sexual and exploitative attitudes and behaviors in gangs and groups, and Coy et al. (2013) on adolescents.

6. A positive (affirmative) understanding of sexual consent characterizes the English, Canadian, and many of the American criminal laws. In England and Wales, s. 74 of the Sexual Offences Act 2003 defines consent as having been present when an individual "agreed by choice, with the freedom and capacity to make that choice." The Canadian Code (s. 273.I) requires "the voluntary agreement of the complainant to engage in the sexual activity in question." The California Penal Code s. 26I.6 refers to "positive cooperation in act or attitude pursuant to an exercise of free will."

7. Constraints on space preclude a fuller account of the evidential or procedural dimensions of this point as it might arise in a trial; my point here is simply to highlight a broadly speaking "liberal" legal perspective on the traditional sexual script and a feminist critique of the same. 
Reece (2013) has argued recently that to credit indirect, ambivalent, and ambiguous words or actions as consent cannot amount to "rape myth acceptance," since in fact we do live in a culture in which such ambivalent words or actions actually are treated as such by sexual agents who enact the traditional sexual script. Reece therefore calls these "sex myths": less accurately thought of as necessarily false beliefs about rape and more accurately as beliefs about sex that may be true or false depending on the context. She concludes that since no one thing (not even "yes") means consent in every case, indirect and potentially ambiguous cues may constitute consent cues in certain cases according to the normative expectations of men and women, allowing for the possibility of miscommunication (46I-465). In the context of a rape trial, for example, the task for jurors is thus to draw out the correct legal implication from a set of facts that are themselves already embedded in an existing sexual culture of meanings and norms. The dual and ambivalent character of the traditional sexual script is thus the nub of the problem of identifying victimization.

Reece's comments provoked controversy because, by suggesting that something like "come in for coffee" might actually stand in for explicit consent to sex in the minds of individuals following the traditional script, she appeared to reinforce the very myths that feminist scholarship has so vociferously sought to combat. And although she acknowledges the implication of her argument-that "the everyday taken-for-granted normative forms of heterosexuality work as a cultural scaffolding for rape" (465) Reece has been criticized for treating this "scaffolding" merely as a background against which jurors form their judgments more or less neutrally. She arguably therefore fails fully to appreciate the impact of a sexist and patriarchal heterosexual culture upon jurors' attitudes (Conaghan \& Russell 20I4, p. 29-3I).

But however uncomfortable it may be, it is precisely this duality of the traditional sexual script—and the possibility that what we call "myths" may actually be true for some people in the way they enact their preferred sexual scripts - that is relevant for our examination of the framing of sexual victimization. Unless we are prepared to believe that the traditional sexual script and rape are necessarily one and the same (i.e., that it is essentially and merely a script that is imposed coercively upon women by men who rape), then discerning the difference between rape and sex will sometimes be finely balanced, and based on contextual clues about the meaning of ambivalent words, actions, and inactions. This does not mean 
we must reject Conaghan and Russell's (20I4) affirmation that the definition of a rape myth may include beliefs that are (at least in some contexts) true. Indeed, a definition of rape myths now widely accepted within feminist circles_-"descriptive or prescriptive beliefs about rape (i.e., about its causes, context, consequences, perpetrators, victims, and their interaction) that serve to deny, downplay, or justify sexual violence that men commit against women" (Gerger, Kley, Bohner, \& Siebler, 2007; cited by, among others, Temkin, 20IO, and Ellison \& Munro, 20I0)—is broad enough to include both true and false beliefs. ${ }^{8}$ However, this duality in the traditional sexual script opens up the possibility of non-victimizing, non-coercive sex without directly or explicitly communicated consent. The crucial point of departure between a carceral feminist framing of the traditional sexual script and the view taken here in challenging that framing lies therefore in thinking about how central victimization is to that script, and the extent to which scepticism toward a rape claim based on what we know about sexual script adherence can justifiably be condemned as recourse to a revictimizing myth endorsement. The next subsection explores sociological sex research that speaks to this ambivalence between the presence and absence of consent cues in enactments of the traditional sexual script.

\section{B. Living the Traditional Sexual Script: Indirect and Ambivalent Consent Cues in Sex Research}

In framing gendered sexual victimization, the troubling question about whether anything other than a fully unambiguous, direct, and unconstrained agreement might constitute valid consent lies at the heart of a debate about the relationship between the traditional sexual script and rape. There are some who argue that for women to bear the responsibility of saying "no" in contexts in which silence might be taken for "yes" is necessary to avoid convicting and punishing men who lack mens rea (Panichas 2006, p. 634-635; Dsouza, 2013). On the other hand, the idea that law should give credence to the view that silence or passivity might

8. Gerger et al. explain (2007) that they arrived at that definition because it is "more expedient to define rape myths not as false, but rather as 'wrong' in an ethical sense," and because empirical falsification and prevalence are "better treated as empirical problems rather than matters of definition" (423). However, the tendency within that literature to think of these beliefs as necessarily "highly spurious" (Ellison \& Munro, 20Io, p. 782) if not downright "false" (Temkin, 20IOp. 715) is also fairly evident. 
ever be allowed to stand in for actual consent strikes others as exposing a dangerous sexism at the heart of traditionally scripted sexual norms that anticipate such passivity only in women (Coy et al., 2013, p. 60). On this view, to give the accused such an opportunity problematically shifts responsibility and blame for rape from him onto the complainant and hence more often than not onto women (Clark \& Carroll, 2008; Conaghan \& Russell, 20I4; Hickman \& Muehlenhard, 1999). It furthermore seeks to find excuses for male coercion in the sexist and patriarchal structures of culture that to a certain extent legitimize male uses of "verbal coercion, psychological pressure, and (within limits) physical force" as a part of "normal heterosexual seduction" (Ellison \& Munro, 20IO, p. 792).

But if our aim is to understand how victimizing and coercive sexual behaviors are different to non-victimizing and non-coercive behaviors, then critiquing the gender imbalances in the way the traditional script plays out cannot be the whole picture. That individuals feel that reliance on nonverbal initiations and consent cues are both sufficient and preferable is reported by, for example, Humphreys (2007) (69\% of male respondents in a Canadian university and $44 \%$ of females) and by Vannier and O'Sullivan (20II), and that "no response" as a way to signal consent is used by both men and women is reported by Hickman and Muehlenhard (1999). Lim and Roloffs (1999) research on the responses of American undergraduate students to various impairments to consent, reports a fairly widespread acceptance that both verbal and nonverbal cues may constitute consent in the absence of coercion or manipulation.

In a study of female undergraduate students' sexual experiences in Kansas, Peterson and Muehlenhard (2007) report that "individuals sometimes consent to unwanted sex and sometimes do not consent to wanted sex," and that sex can be experienced by both men and women as enthusiastically wanted without being consented to at all (8I). Their study sheds useful light on whether, in the endeavor to distinguish victimizing from nonvictimizing sexual behavior, what we look for is explicit and direct consent necessarily or something else. Although their research subjects' selfreported experiences of "wanted-but-unconsented-to" sex were in many cases found to be instances of unacknowledged rape for which women

9. On this point, see also Conaghan and Russell (2014), Clark and Carroll, (2008), Ellison and Munro (2013), Littleton (20II), Frith and Kitzinger (1997), and Kitzinger and Frith (1999). 
found ways to blame themselves, ${ }^{10}$ this was not always the case. Quoting Peterson and Muehlenhard:

$[\mathrm{N}]$ ot all experiences in which the woman was intoxicated seemed coercive or nonconsensual. For example, we excluded one woman from our rape group although she reported having been drunk and high on marijuana. She wrote, "The guy was hot and drunk sex is the best" (Participant \#R-o63, questionnaire response), and she described enthusiastically participating in the intercourse. (2007: 83)

Peterson and Muehlenhard are here referring to a woman who was unable to consent at the relevant time, and who furthermore cannot be assumed to have given consent prior to becoming intoxicated. ${ }^{11}$ As such the experience described may be classified as an example of sexual victimization under the Sexual Experiences Survey (SES), a I3-item measure used by a number of studies, including Turchik et al. (2010), considered below. ${ }^{12}$ Of course, in this particular instance the woman concerned had no intention of making a complaint about what happened to her. But if we start from the premise that active and direct consent serves as a bright line between victimizing and non-victimizing sex, then Peterson and Muehlenhard's decision to exclude the woman quoted above from their "rape group"-because her case "seemed" to the researchers not to be nonconsensual - must be troubling, since it amounts to saying that in some cases legally valid consent is not even necessary. Must we say, therefore, that the researchers' failure to condemn such an incident as sexual assault or rape and to identify the woman as a crime victim is symptomatic of rape myth

Io. An example of such a respondent, whom Peterson and Muehlenhard classify as a victim of rape who failed to acknowledge her victimhood, is described thus: "Another [respondent], who was drunk to the point of unconsciousness during the intercourse, wrote, “... when I get drunk I am usually horney [sic] so I probably wanted it as bad as him"” (Petersen \& Muehlenhard, 2007, p. 82).

II. Prior consent would be relevant for defending a rape or sexual assault charge in some jurisdictions (such as England and Wales) although not in others (such as Canada).

I2. Assuming the woman was conscious, the two situations relevantly defined in the Sexual Experiences Survey Long Form Victimization (SES-LFV) defines as victimizing are: "Using me sexually after I had taken drugs and was conscious but too incapacitated (out of $i t$ ) to give consent or stop what was happening" (f), and "Using me sexually after I had been drinking alcohol and was conscious but too intoxicated (drunk) to give consent or stop what was happening" (j). See Koss et al. (2007). 
acceptance, and an attitude that is unacceptably untroubled about male exploitation of women who are incapable of giving consent? ${ }^{13}$

It is submitted here that such a response, while ostensibly one that errs on the side of protection for the most vulnerable, would be the wrong one. Furthermore, that such a reading of that study seems to be a logical implication of carceral feminist thinking is indicative of its clumsily totalizing and essentializing approach to theorizing sexual experiences. Certainly, being wary of analyses of sexual activity such as Peterson and Muehlenhard's may promote critical engagement with the norms of consent-getting in pursuance of more egalitarian, mutually pleasurable and less risky sexual scripts than the traditional one (Coy et al. 201365; Beres 20I0). But at the same time, we must not lose sight of the danger that such wariness, when it leads to particular studies being excluded from consideration, also promotes a carceral agenda that is sometimes at odds with the subjective experience and self-perception of potential "victims" themselves.

\section{The Traditional Sexual Script and Gender Stereotypes in Carceral Feminism}

Having outlined the "cultural scaffolding" shared between sex (enacted along the lines of the traditional sexual script) and rape (in its counterstereotype form, involving acquaintances, partners and ex-partners) it becomes clear how, in carceral feminist thinking, the roles of abuser and victim may become solidified and hence sexual coercion mischaracterized. It is a familiar starting point for studies on sexual victimization to assert that, in general, men do the victimizing and women get victimized; that this arrangement is deeply embedded within the fabric of our patriarchal society and that a primary purpose of scholarship is to develop methodologies that allow this reality to be exposed and depicted most accurately. ${ }^{14}$

I3. See, for example Temkin (20I0), who claims that women who are "unable to express lack of consent by words or actions" are excluded from the popular understanding of rape due to the allegedly established and deeply ingrained belief that "a woman can always withhold consent to sex no matter how drunk she is" (715-716). Since in the extreme case of victim intoxication that Temkin refers to, this "belief" is so clearly nonsense (and Temkin must be right to describe it as "defy[ing] common sense"), she may be taken to be referring to instances such as Peterson and Muehlenhard's participant \#R-063, quoted above, who reported desiring un-consented-to sex.

I4. The following three extracts are illustrative here: "rape and sexual violence function as tools of social control through which men keep women in a state of fear [and at home]" 
But does this mean that in terms of the meaning of these roles, perpetrator and victim are necessarily gendered identities, and that victimization is essentially a problem of masculinity? My concern here is not to try to rebut the empirical claims about the relative numbers of men and women perpetrating coercive behaviors, although there is research that suggests such a line of argument may be warranted. ${ }^{15}$ But at the same time, there are dangers here in conflating general trends and the facts of particular cases that do not fit this gendered picture. For example, Wallerstein (2009) reserves for women alone the consequences of being made "vulnerable" and potentially victimized by becoming intoxicated, and in this sense seems to turn the feminine identity of the victim into a necessary truth. In combatting the responsibilizing myth that a woman retains the capability for withholding consent "no matter how drunk she is" (Temkin, 20IO, p. 715), Wallerstein depicts the self-intoxicated woman as necessarily in-capable (and hence victimized by sex) no matter how determined and insistent she is either at the time, beforehand, or afterward. Wallerstein achieves this I8o degree reversal of mythical thinking by conflating "unable to consent" and "consented where she would not have while sober" (333), describing as "a matter of (normative) fact" her belief that a woman [and not a man] is incapable of consenting in that instance $(334,335)$. A man who has sex with a woman whose inebriation makes her liable to consent when she would not have done while sober is "predatory" and law should not legitimize predation (337).

Although the double sexual standard in Wallerstein's argument may seem crude and clumsy to anyone that does not already share her (normative) vision, the framework of male aggressor-female victim is so well

(Abrams, Viki, Masser, \& Bohner, 2003, p. III); "Research on sexual assault victimization and perpetration has consistently found a gap between the percentage of women who report experiencing coerced, unwanted sexual activity and the percentage of men who report having coerced or forced a woman to engage in sexual activity" (Clark \& Carroll, 2008, p. 6I6); “avoiding language like 'rape' [in studies of men's self-reporting of sexual aggression] is important because... men who engage in sexual aggression are even less likely [than women] to use terms like 'rape' or 'sexual assault' to describe their behaviour. Less threatening, more colloquial language is likely to produce more accurate responding than items that rely on legal terms" (Strang, Peterson, Hill, \& Heiman, 2013, p. 459).

15. See Russell and Oswald (200I) who, using a modified version of the SES to survey 285 female students in America, found that "[f]ifty-two (I8.2\%) participants reported engaging in some type of verbal or physical coercive behavior to obtain sexual intercourse [including] thirty (26.1\%) women [who reported] 'becoming so sexually aroused that they felt it was useless to stop even though the partner did not want to have sex"' (Io8). 
established that it seems to make other ways of looking at sexual coercion difficult. The few examples of feminist-informed empirical studies that have tried to engage with the risk of this framework engendering stereotypes underline this difficulty. For instance, Ellison and Munro (2009) promisingly insist that it is problematic that most of the subjects of their mock jury research seemed to assume that the traditional sexual script is natural and inevitable (298). Similarly, Fagen and Anderson (2012) admonish fellow researchers on sexual coercion for largely ignoring men's experiences of unwanted and coercive heterosexual contact. However, both of these articles end up confirming precisely the problems they identify. Ellison and Munro (2009) cite "the excesses of male sexuality" as the cause of unwanted sexual touching (302), and in this way pull back from the potentially conflicting implication of their earlier approval of a minority of jurors who voice a view that women as well as men are capable of being sexually "predatory" (298). Fagen and Anderson (2012) meanwhile frame men's narratives about having been sexually coerced or taken advantage of by a woman as illustrating, not coercion or victimization, but merely men's discomfort with and disdain towards (a) women who take the initiative in sex, (b) woman who are "slutty," and (c) women who pose a challenge to the masculine desire and/or need for sexual control and dominance (262-263, 268-269).

Fagen and Anderson's failure to "see around the corners"16 of a theoretical framework of male domination and female subordination is particularly abject, given their claim to be responding to a dearth of empirical studies on male experiences of victimization. In their study of male reports of being sexually coerced, two examples of that failure are illustrative here. One of their interviewees, Noah, describes an experience at the age of I8 that made him feel "ashamed and empty" and "coerced" after a female driver who had picked him up while hitch-hiking suddenly pulled the car over, wordlessly undid his trousers, and performed oral sex on him. Fagen and Anderson's analysis is far from sympathetic:

$[\mathrm{H}] \mathrm{e}$ was not only complicit in the woman's initiatives, but he also sought to regain control over the situation by attempting to touch her sexually. However the woman repeatedly refused these attempts, which made Noah feel disempowered. (2012, p. 267) 
A second interviewee, Tyler, describes how, at the age of 20 , he passed out at a party, and a girl he had met "realized that I was passed out and basically did what she wanted to." Noting that this made him feel "pissed off" when he found out later what had happened, Fagen and Anderson do not admit of the possibility of victimization. Instead they read his reaction as being motivated simply to reassert his dominant status as a man over women in general: "his anger was associated with the fact that he was not the one who (directly or indirectly) initiated the sexual contact" (268). Sticking firmly to a framework in which only men can be sexual aggressors and only women can be victims, a narrative about female coercion and male victimization is simply not thinkable. That this is problematic is exposed by empirical research indicating that coercion may be less about masculinity as such than sex role enactment. Russell and Oswald (200I) found that women who reported using verbally and/or physically coercive strategies to gain sex from an unwilling male partner were more likely to score highly on "femininity," and the researchers suggest that "excessively feminine, coercive women perceive their strategies as being 'seductive' rather than coercive" and hypothesize that this may reflect self-perceptions of "sexually coercive men high in masculinity" (II2). A feminist theorization of the traditional sexual script provides a way of seeing the latter (coercive male "seduction") as rape, potential rape, or at least as rape-approving. But this gives us no such understanding of the former (coercive female "seduction").

\section{QUESTIONING THE PREVALENCE AND INFLUENCE OF THE REAL RAPE MYTH}

Arguably the single most important aspect of the traditional sexual script for present purposes is the implications attributed to it as regards popularly held attitudes and beliefs about rape. According to carceral feminist arguments as characterized so far in this article, sexually coercive male behavior is so deeply normalized that rape involving an intimate partner (Littleton, 20II; Rumney, I999; Anderson, 2010), a promiscuous woman (Russell, 2013; Anderson, 2010), drunken sex (Gunby, Carline, \& Beynon, 2013), or emotional pressure (Russell, Oswald, \& Kraus, 20II) may become invisible. A variety of studies advance this view of a popularly endorsed and scripted gulf existing between the myth of real rape and rape in its more 
typical forms ${ }^{17}$ that explains negative attitudes toward many rape complainants and high attrition rates in rape trials. Rape myth acceptance has been correlated positively in the research literature with such factors as being male (Gray, Palileo, \& Johnson, I993; Newcombe, van den Eynde, Hafner, $\&$ Jolly, 2008), being male and believing that sex is about power and domination (Chapleau \& Oswald, 2013), being male and believing that women are generally more virtuous than men ("benevolent sexism") (Abrams et al., 2003; Masser, Lees, \& McKimmie, 2009), being male and not being on board with feminism, its importance, and the reasonableness of its and women's demands ("hostile sexism") (Rudman, Fetterolf, \& Sanchez, 20I3, Stahl, Eek, \& Kazemi, 20IO), being sexist generally (Duran, Moya, Megias, \& Viki, 20Io), and believing that society and its systems are currently just and fair (and consequently that people get what they deserve) (Chapleau \& Oswald, 20I3). ${ }^{18}$

We may divide the research literature into a number of categories: mock jury studies, vignette-response analyses, rape scripts, and nonempirical (theoretical or meta-study) analyses. For the first category, Ellison and Munro, over the course of a number of articles, identify the real rape myth (and its difference from "normal sex") as responsible for making juries unduly sceptical of complainants in alleged acquaintance rape situations. They report how the closer the facts of an alleged rape incident looked to jurors' notions of normal sex (specifically, involving a normal-seeming rather than predatory man, taking place at her home rather than anywhere too "seedy" (2009, p. 300), and seemingly following a "seduction script" as opposed to that of a "prototypical rape" (20IO, p. 794)), the more difficultly the jurors had in convicting. The researchers report that jurors seem to look to signs that the incident in question may have been one of raunchy or rough sex (2013, p. 319) as opposed to rape, in which the facts of the parties' being, for example, former lovers recently separated, drinking wine together in the woman's own home (2013, p. 3II-3I3), and there being only superficial marks and scratches on the woman's body-all of which contradict the real rape stereotype-are factors preventing jurors from convicting. Related to this "mock-jury" approach, but also distinct in some

I7. The latter sometimes being referred to, in North American legal contexts at least, as "simple" rape (Panichas, 2006).

I8. Confusingly, Gunby et al. (2013) report also that being female is positively correlated with suspicion of the victim or complainant of "simple rape." 
important ways, vignette response studies try to determine how varying certain factors affects the way people respond to a fictional potential rape scenario. An example of such a study is Schuller, McKimmie, Masser, and Klippenstine (2010), which confirms that popular perceptions of rape victims are associated with gender and victim stereotyping. The study reported that, when presented with a complainant who is a stereotypically good or responsible mother, the victim's visible emotions were significant in determining how favorably respondents regarded her complaint. Predictably, such complainants that behaved more like the stereotype of the real rape victim-tearful and upset as opposed to calm and controlledwere more likely to be regarded favorably.

Representing rape scripts research, Krahé and colleagues (2007) argue that adolescents whose own imagined rape scripts re-tell a version of the stranger rape script are less likely to acknowledge or recognize actual rape and sexual coercion when it happens to them (317); Turchik et al. (20I0) confirms this in the context of women's experiences of sexual coercion, reporting that some women may be less equipped to avoid and resist sexual victimization if they are accustomed to thinking only of stranger or "blitz" rape; Lim and Roloff (1999) report that respondents were more likely to regard "inappropriate" sexual behavior (e.g., sexual behaviors in situations involving the giving or taking of alcohol or marijuana, where the male is persistent or already involved sexually with someone else) to be short of rape when they also indicated acceptance of the "rape script" in which the rapist is a violent stranger (19). Littleton, Tabernik, Canales, and Backstrom's (2009) research on "hook-up" sex and the dangers of coercion in that context found that young people drew distinctions between "bad hookups" on the one hand (i.e., sex between loose acquaintances that goes wrong somehow) and "rape" (i.e., stranger rape) on the other (8oo-802).

To be critical of sexist mythical thinking and of the disproportionate impact it may have on women is of course a thoroughly justifiable response to tackling prejudices that would stymie prosecutions of the much more typical rape scenario. That failures of law enforcement to bring rapists to justice and of juries to convict them are in one way or another explainable by widespread acceptance of the real rape myth is within feminist discourse a widely and regularly affirmed view, and provides an important driving force for calls for law reform and education. It should not be surprising then that attempts to introduce doubts about whether rape myth acceptance does in fact represent the truth about popular attitudes and beliefs 
about rape are often regarded as a betrayal of this important project, and are therefore met with fierce rebuttals. For example, Conaghan and Russell (2014) respond to Reece's (2013) criticism of feminist rape myth acceptance research in the strongest terms:

$[\mathrm{H}]$ er failure to engage with feminist literature on rape other than in the narrowest, most exclusionary terms, yields an approach which impedes rather than advances public understanding and panders to a kind of simplistic thinking which cannot begin to grapple with the complexity of the phenomenon that is rape. (27)

This sort of response may be indicative of a perfectly understandable sense of frustration and unease amongst carceral feminists, for whom rape myth acceptance is central to understanding rape and sexual assault in its wider context. But to the extent that this understanding is both an influential one and open to question, there are good reasons for pursuing those questions and taking them seriously. These reasons have everything to do with the real consequences for both women and men of allowing our theorizations to become fossilized articles of faith that close out other voices. At this point, therefore, this article offers criticisms of some examples of feminist rape myth acceptance research.

\section{A. Criticisms of Rape Scripts Research}

In some rape scripts studies for example, the influence of the real rape myth is postulated from the fact that, when prompted to write about an imagined "typical" rape and a sexual encounter that goes "bad," research subjects will often distinguish between the two by imagining a rape that includes some of the elements of the real rape myth (for example, by imagining it to occur outside, or involving a pathological stranger), while generally not anticipating rape as a potential outcome of a casual sexual encounter that goes "bad." An article by Littleton et al. (2009) provides an example of such an approach, which by asking subjects for two separate narrative accounts, may have encouraged this very discrepancy. ${ }^{19}$ Having been asked to produce a script imagining a "bad hook-up" scenario and a separate script

I9. "Specifically, a sample of US college women provided written narratives describing their ideas regarding typical rapes and typical bad hook-ups" (p. 795). 
imagining a rape scenario, it must be unsurprising that a large number of respondents would write two different sorts of narratives. Does this mean they endorsed rape myths? Perhaps, but equally they might have been led by Littleton and colleagues' instructions to think they would be shortchanging the researchers if they wrote to two very similar scripts.

Another example of rape-myth acceptance being drawn in questionable ways from scripts research is Turchik et al.'s (2010) study of 339 undergraduate college women in an American university. Turchik and colleagues report that women's imagined scripts of "an unwanted sexual advance" (78) are a predictor of vulnerability to victimization ${ }^{20}$ when those scripts included real rape elements such as "a severe outdoor assault perpetrated by someone they knew less than a month" (8I). In other words, women who, when asked to write a script for an unwanted sexual advance that included "real rape" elements, were more likely to report moderate or severe sexual victimization both in their past (from the age of I4) and in an eight-week follow-up period after submitting their narratives. Of course differences in life experience may color an individual's imagination. But the study exposes a number of methodological difficulties involved in drawing any deeper connection than this. Firstly, the study builds into its analysis an assumption that an "unwanted sexual advance" is necessarily experienced as victimizing; indeed "unwanted" is grouped together with "coercion" in the definition of a "moderate" level of sexual victimization in these researchers' own three-level coding scheme (78). Secondly, reported instances of "victimization" are taken by the researchers to indicate women's failure to recognize "important risk cues" due to their falsely believing in the myth of stranger "blitz" rape (82). Turchik and colleagues do not go into detail about the precise nature of the actual sexual victimization reported by the women, but assuming that this represents the range of coercive and manipulative strategies identified in the SES, then is the very opposite analysis not equally possible here? That is to say, in reporting being sexually victimized, are those same women not demonstrating that they really do recognize sexual coercions as such even if these experiences do not fit the stereotype of stranger rape, and hence that we actually learn very little, if anything at all, from their imagined scripts? 


\section{B. Criticisms of Mock-Jury Research}

Mock jury research similarly may be seen to downplay or overlook the possibility that something other than myth acceptance and stereotyping might explain jurors' apparent failures to convict. Ellison and Munro (20I0) place a strong emphasis on the supposed ability of their mock jury research to reveal the widespread influence of mythical thinking where direct questioning is ineffective. People will typically be able to identify and will explicitly disavow rape myths (including the real rape myth) when asked about their attitudes directly. But placing them on a mock-jury and tasking them with interpreting events constituting an alleged acquaintance (or otherwise counter-stereotypical) rape indicates rape myth acceptance working on a much deeper level. Ellison and Munro (2010) regard this finding as an important break-through in identifying the prevalence and impact of rape myth acceptance attitudes. However, there are also reasons to be suspicious of just how much it can really tell us. In these final pages of this article, we examine two examples of the tendency to overdraw the significance of rape myth acceptance in mock jury research: first, regarding beliefs about the location of rape (since stereotypical real rape is supposed to happen outside), and second, beliefs regarding the possibility of miscommunication in counter-stereotypical situations.

Firstly then, Ellison and Munro (2009) are of course quite right to warn of the implications of assuming an incident to be more likely rape if it takes place outside or in a seedy public place like a hallway rather than in the woman's own home. ${ }^{21}$ But if we are to follow Ellison and Munro in regarding that sort of thinking as evidence of jurors accepting the real rape myth, we might also consider what implications this has for other feministinformed studies that seem to attribute significance to location and setting. What are we to make of, for instance, research by Berelowitz, Clifton, Firmin, Culyurtlu, and Edwards (2013) warning that peer-on-peer sexual assault by boys and young men on girls and young women takes place "often in public places such as stairwells and alleyways, as well as in their own homes" (IO5)?

2I. 'Jurors emphasized the 'inappropriate', 'seedy', 'desperate', 'animalistic' and even 'unnatural' connotations of having sex in a hallway, and suggested that this location bolstered the complainant's account, since had she consented to intercourse 'she would have invited him to a more comfortable environment"' (p. 299). 
If we are to be consistent with Ellison and Munro's understanding of the sorts of clues from which it is appropriate to draw conclusions about jurors' rape-myth-accepting attitudes, should we read Berelowitz and colleagues as trying to say that sexual assault takes place anywhere, and that stairwells, alleyways, and the home are all simply and equally examples of what "anywhere" includes? This would be an odd way to indicate that location lacks significance. But at the same time it is inconceivable to me that these authors would admit to endorsing (albeit inadvertently) the real rape myth, and I would be inclined to give them the benefit of the doubt. What needs to be borne in mind is that both Ellison and Munro's jurors and Berelowitz and colleagues are engaged in articulating the difference between rape and consensual sex without the help of any obvious bright line of consent explicitly given or refused. Given that crucial absence, it is not difficult to imagine that the un-homely and seedy locations referred to would have served as a lightning rod to considerations of the nature of exploitative and agency-limiting conditions. But it is something of a leap to move from this to the conclusion that it is rape myth acceptance that is at work in one set of deliberations but not the other. Being struck by the seediness of a location and being alert to the possibility that sexual consent given in such circumstances might also carry the possibility of constraints upon a woman's freedom to consent, might well signify something about commonly endorsed norms regarding the appropriate time and place for sex. But this does not necessarily imply a belief that a woman who claims to have been raped in her own home (i.e., somewhere regarded as being the appropriate place for sex) is not to be believed.

A second implication of rape myth acceptance is that an alleged rape that lacks the stereotypical qualities of real rape may be explained away and excused as mere "miscommunication." Two important examples of this implication are attitudes toward incidents involving alcohol, and incidents involving intimate partners whose sexual activities may not typically involve communication about consent at all. To take the first of these examples, Gunby and colleagues (2013) argue that jurors will often wrongly take the accused's own intoxication into account in considering his "moral responsibility" for his mistaken belief in consent, implying not only that jurors are misapplying the law on reasonable mistaken belief, but also that jurors are importing a foreign moral concept because they want to find some way to excuse men who rape (99-100). Finch and Munro (2007) follow the same line of thinking in their mock-jury study involving an 
intoxicated complainant. Finch and Munro criticize jurors who were prepared to believe that the accused simply "misunderstood" the woman's behavior, particularly if his (as well as her) judgement might have been impaired by drink (603), so long as there was no evidence that he deliberated got her drunk in order to take advantage of her. For both Gunby and colleagues (2013) and Finch and Munro (2007), alcohol is a crucial aspect of the scaffolding of "rape culture," according to which intoxication is popularly regarded as reducing men's responsibility while increasing women's responsibility, and encoding the normalization of male sexual aggression against women. Against this context, to think of miscommunication as explaining a complaint is simply another version of the story of rape myth acceptance. This is because, for Finch and Munro, the sorts of distinctions that jurors make when intoxication is part of the scenario- - between voluntary and involuntary intoxication and between alcohol and date-rape drugs - are all part of the discourse of victim-blame and of a general "disapprobation of female intoxication" (2007, p. 607).

The problem with that analysis is that, in reading the distinctions being made by jurors as finding ways to blame the complainant or victim rather than the defendant, Finch and Munro (2007) do not leave sufficient room for jurors to consider questions relevant to the accused's guilt, including mens rea. It is at the very least plausible to suppose that the mock jurors criticized by Finch and Munro were trying to articulate something perfectly appropriate: if there was evidence that the accused deliberately went out of his way to get the complainant into a helpless state in order to have sex with her, then evidence of mens rea might be more straightforwardly established. In the absence of such evidence of the sort of malicious intent that we might associate with the stereotypically pathological rapist, they are faced with the more difficult task of determining the accused's guilty mind from a set of clues that are (again) embedded within a traditional sexual and social script. There is of course real value in Finch and Munro's analysis in that it highlights the danger that coercive strategies may exploit such a script by hiding within it. As noted above, this is a danger recognized by Reece (2013) in her critique of feminist rape myth research. However, Finch and Munro's argument moves too quickly and too smoothly from (a) highlighting the possibility that stereotypes might be affecting jurors' consideration of consent and mens rea against cultural norms, to (b) the conclusion that this reveals sexist rape myth acceptance. This is not to suggest that there is nothing problematic in such a culture or that rape myths play no role. 
But at the very least there is a question to be asked here with respect to the persuasiveness and reliability of Finch and Munro's framing of the possibilities for miscommunication as a myth.

The second example of acceptance of the real rape myth leading to acceptance of the miscommunication excuse involves intimate relationships, and connects our discussion here once more with the empirical sex research considered above. An accused man might contend that since he and the complainant had become accustomed to silent, passive, or indirect consent cues, he reasonably failed to realize on a particular occasion that this response (or lack of response) actually constituted a lack of consent on her part. One theme that comes through a number of the sex research studies in terms of both beliefs and practise is that the perceived need for explicit consent is inversely proportional to the degree of intimacy and familiarity between the parties (Humphreys, 2007; Muehlenhard \& Hickman, 1999; Vannier \& O’Sullivan, 20II). However, since the real rape myth anticipates a rapist to be the opposite of a committed sexual partner (i.e., a stranger), does crediting such beliefs and practises with legitimacy and lawfulness amount to endorsing the myth? Certainly it is because mock jurors look to signs of a pre-existing sexual relationship in discrediting a complainant's account that they are criticized for indulging in rape myth acceptance (Ellison \& Munro, 2009, 2013; Littleton et al., 2009; Littleton, 20II). And in cases in which consent is in doubt and in which the accused tries to use the prior existence of a sexual relationship to bolster his defense, ${ }^{22}$ appeal judges and (for example) media commentators have been criticized as endorsing the myth that heterosexual relationships are a context in which safety may be anticipated (Busby, 20I2; Gotell, 20I2; Craig, 20I4). ${ }^{23}$

22. As in, for example, the Canadian Supreme Court case involving erotic asphyxiation and subsequent unconscious sex ( $R$ v. J.A. [2OII] SCC 28).

23. In legal jurisdictions on both sides of the Atlantic, beyond those varieties of coercion and agency-limiting conditions and strategies listed in rape and sexual assault statutes, the question of what sorts of pressure and persuasion count as sufficiently coercive to invalidate a complainant's ability to consent is a matter of some debate. The problem of getting those who may have used such pressure and/or persuasion to see their behavior as ethically or legally problematic may account for discrepancies between studies indicating that men's self-reported uses of coercion is generally considerably lower than women's self-reported experiences of sexual victimization. See Strang et al. (2013) for a useful study on methodological challenges associated with this. 
However, without challenging the factual basis for the claim that a rapist is more likely to be a current or former intimate partner than a stranger, let me reiterate the criticism of this kind of thinking already outlined. In finding the right way to frame the question of whether the accused is guilty of rape or sexual assault, the combined dangers of mythologizing, stereotyping, and essentializing represent a series of traps on either side of us. On one side we would certainly be accepting a myth if we were to say or imply that consent is less of an issue in the case of partners or ex-partners than of strangers. But on the other side, to exclude contextual matters that would indicate the possibility of consent or a belief in consent and hence an absence of mens rea, transforms a perfectly legitimate concern for highlighting victimization and where it happens (i.e., in relationships) into an immutable and necessary Truth (Khan, 20I4). The fact that we know from sex research studies that in established sexual relationships consent-talk does become more dependent on nonverbal and indirect cues (Humphreys, 2007; Vannier \& O'Sullivan, 20II; Hickman \& Muehlenhard, 1999) is certainly a cause for concern about an apparent lack of awareness about the dangers of coercion within sexual relationships. However, this same research must also be relevant for reflecting on whether to categorize miscommunication as a false belief (Hansen, O’Byrne, \& Rapely, 20I0; O’Byrne, Rapely, \& Hansen, 2006) or in fact a realistic possibility (Tadros, 2006, pp. 529, 54I; Wallerstein, 2009, p. 335). ${ }^{24}$

Conaghan and Russell (2014) claim that feminist research on this topic is always cognizant of rape myths as "time-bound and contextual," and as such a matter of empirical verification and falsification rather than abstraction (33). But is this really a justifiable claim? If jurors' reluctance to convict when confronted with an apparent overlap between traditional sexual script adherence and a rape allegation (or the reverse of that, as in the example above of the implications to be drawn from a "seedy" location), is itself taken to demonstrate rape myth acceptance, then this rather implies that there is really ever only one right result in such a scenario. Far from showing commitment to "context," this sort of thinking shows instead commitment only to an abstract theoretical framework informing a political position.

24. Note that according to Gerger et al.'s (2007) definition of rape myths, characterizing miscommunication as a myth would not necessarily require that it be proven untrue. 


\section{CONCLUSION}

To the extent that the studies examined here premise their framing of rape and sexual assault on a necessary connection between the traditional sexual script and victimizing or coercive sex, they are open to legitimate concerns and criticisms. In offering its critique, this article should not be taken as endorsing the traditional script itself, which is of course problematic and even dangerous in many ways. For example, it fails to guarantee mutuality or equality in the roles played and the degrees of pleasure for men and women, and it fails in any obvious way to ensure that sexual behaviors are non-coercive and non-victimizing. We must certainly acknowledge that a good deal of sexual behavior following the traditional script anticipates a passive female who participates without enthusiasm or expectation of pleasure; but that is something different to coercion, and limitations on space prevent a full exploration of that distinction here. ${ }^{25}$ This article also acknowledges the empirical possibility of women themselves miscategorizing their experiences as consensual because they are unable or unwilling to acknowledge that a trusted friend or partner may have coerced them. In anticipating that consent will not always be directly communicated (if it is communicated at all), this is a script that shares its basic scaffolding in part with rape. But the central argument of this article has been that this is a matter of overlap rather than equivalence; notwithstanding these admitted constraints and the dangers that coercion may be obscured by the traditional script in particular contexts, research on consent cues suggests that authentic sexual agency remains possible. Whether an alleged instance of sexual victimization really is so is hence a matter of factual demonstration in that particular case.

This article is fully in agreement with removing sexist stereotypes from jury deliberations and from perceptions of rape and its perpetrators and victims generally. However, in pursuing this project with a carceral objective in mind, we should be wary about replacing one set of myths and stereotypes (that applies abstract patriarchal norms to undermine the credibility of complainants and sympathy for victims) with another (that applies abstract gender norms to narrow the defendant's ability to defend himself). The argument of this article is offered, not to oppose perspectives on criminal justice that are informed by feminist theorizations and empirical studies, but 
to argue that, like all important insights, those advanced in the cause of gender justice must remain self-critical in light of the limitations that come with contextual differences between cases. Unless we are prepared to criminalize non-victimizing and non-coercive sexual behaviors, then it may be necessary to accept that, in judging instances of alleged sexual coercion and victimization, there is a legitimate place for indirect and potentially ambivalent signs and cues (Munro, 2005, p. 348-350). It seems to me implausible to insist that the sex research literature does not at the very least call into question some of the more abstracting approaches to victimizing and coercive sex in the feminist studies identified in this article. As Cameron-Lewis and Allen (2013) argue, we cannot rule out in advance the possibility of sexual behaviors that embrace the danger of coercion and misunderstanding. A truly critical approach to determining when to treat any particular act as a criminal one must take this into account.

\section{REFERENCES}

Abrams, D., Viki, T., Masser, B., \& Bohner, G. (2003). Perceptions of Stranger and Acquaintance Rape: The Role of Benevolent and Hostile Sexism in Victim Blame and Rape Proclivity. Journal of Personality and Social Psychology, 84(I), III-I25.

Anderson, M. J. (20I0). Diminishing the Legal Impact of Negative Social Attitudes Toward Acquaintance Rape Victims. New Criminal Law Review, I3(4), 644-664.

Beckett, H., with Brodie, I., Factor, F., Melrose, M., Pearce, J., Pitts, J., Shuker, L., \& Warrington, C. (2013). "It's wrong ... but you get used to it": A qualitative study of gang-associated sexual violence towards, and exploitation of, young people in England. Office of the Children's Commissioner.

Berelowitz, S., Firmin, C., Edwards, G., \& Gulyurtlu, S. (20I2). "I thought I was the only one in the world": The Office of the Children's Commissioner's Inquiry into Child Sexual Exploitation in Gangs and Groups, Interim Report. Office of the Children's Commissioner.

Berelowitz, S., Clifton, J., Firimin, C., Gulyurtlu, S. and Edwards, G. (20r3). "If only someone had listened": Office of the Children Commissioner's Inquiry into Child Sexual Exploitation in Gangs and Groups, Final Report. Office of the Children's Commissioner.

Beres, M. (2010). Sexual miscommunication? Untangling assumptions about sexual communication between casual sex partners. Culture, Health \& Sexuality, I2(I), I-I4.

Burton, M. (2013). How different are "false" allegations of rape from false complaints of GBH? Criminal Law Review, 3, 203-213.

Busby, K. (20I2). Every Breath You Take: Erotic Asphyxiation, Vengeful Wives, and Other Enduring Myths in Spousal Sexual Assault Prosecutions. Canadian Journal of Women and the Law, 24, 328-358. 
Cameron-Lewis, V., \& Allen, L. (20I3), Teaching pleasure and danger in sexuality education. Sex Education, I3(2), I2I-I32.

Chapleau, K., \& Oswald, D. (2013). Status, Threat, and Stereotypes: Understanding the Function of Rape Myth Acceptance. Social Justice Research, 26, I8-4I.

Clark, M. D., \& Carroll, M. H. (2008). Acquaintance Rape Scripts of Women and Men: Similarities and Differences. Sex Roles, 58, 616-625.

Cossman, B. (20II). Sex and the Unconscious (No, We Aren't Speaking of Freud). Mark S. Bonham Centre for Sexual Diversity Studies, University of Toronto.

Conaghan, J., \& Russell, Y. (20I4). Rape Myths, Law, and Feminist Research: "Myths About Myths"? Feminist Legal Studies, 22, 25-48.

Coy, M., Thiara, R., \& Kelly, L. (20II). Boys think girls are toys? An evaluation of the NIA project prevention programme on sexual exploitation: Final report. Child and Woman Abuse Studies Unit, London Metropolitan University.

Coy, M., Kelly, L., Elvines, F., Garner, M., \& Kanyeredzi, A. (2013). "Sex without consent, I suppose that is rape": How young people in England understand sexual consent. Office of the Children's Commissioner.

Craig, E. (20I4). Consent to a Sexual Risk. New Criminal Law Review, I7(I), I03-I34.

Dripps, D. (1994). Men, women and rape. Fordham Law Review, 63(I), I25-I47.

Dsouza, M. (2013). Undermining prima facie consent in the criminal law. Law and Philosophy, 33(4), 489-524.

Duran, M., Moya, M., Megías, J. L., \& Viki, G. T. (2010). Social Perceptions of Rape Victims in Dating and Married Relationships: The Role of Perpetrator's Benevolent Sexism. Sex Roles, 62, 505-519.

Ellison, L., \& Munro, V. (2009). Of "normal sex" and "real rape": Exploring the use of socio-sexual scripts in (mock) jury deliberation. Social and Legal Studies, I8(3), 29I-3I2.

Ellison, L., \& Munro, V. (2010). A stranger in the bushes, or an elephant in the room? Critical reflections upon received rape myth wisdom in the context of a mock jury study. New Criminal Law Review, I3(4), 78I-80o.

Ellison, L., \& Munro, V. (2013). Better the devil you know? "Real rape" stereotypes and the relevance of a previous relationship in (mock) juror deliberations. International Journal of Evidence \& Proof, I7(4), 299-322.

Fagen, J.L.F., \& Anderson, P. B. (2012). Constructing masculinity in response to women's sexual advances. Archives of Sexual Behaviour, 4I, 26I-270.

Finch, E., \& Munro, V. (2007). Demon drink and the demonized woman: Socio-sexual stereotypes and responsibility attribution in rape trials involving intoxicants. Social and Legal Studies, I6(4), 59I-6I4.

Frith, H., \& Kitzinger, C. (1997). Talk about sexual miscommunication. Women's Studies International Forum, 20(4), 517-528.

Gerger, H., Kley, H., Bohner, G., \& Siebler, F. (2007). The Acceptance of Modern Myths about Sexual Aggression Scale: Development and Validationin German and English. Aggressive Behaviour, 33, 422-440.

Gotell, L. (2012). Governing Heterosexuality through Specific Consent: Interrogating the Governmental Effects of R. v. J.A. Canadian Journal of Women and the Law, 24, $360-388$.

Gray, N. B., Palileo, G. J., \& Johnson, D. (1993). Explaining rape victim blame: A test of attribution theory. Sociological Spectrum, I3, 377-392. 
Gunby, C., Carline, A., Bellis, M. A., \& Beynon, C. (2012). Gender differences in alcoholrelated non-consensual sex: Cross-sectional analysis of a student population. BMC Public Health, I2, 216.

Gunby, C., Carline, A., \& Beynon, C. (20I0). Alcohol-related rape cases: Barristers' perspectives on the Sexual Offences Act 2003 and its impact on practice. Journal of Criminal Law, 74(6), 579-6oo.

Gunby, C., Carline, A., \& Beynon, C. (2013). Regretting it After? Focus Group Perspectives on Alcohol Consumption, Nonconsensual Sex and False Allegations of Rape. Social and Legal Studies, 22(I), 87-106.

Halley, J. (2008). Split Decisions: How and Why to Take a Break from Feminism. Princeton, NJ: Princeton University Press.

Hansen, S., O’Byrne, R., \& Rapely, M. (2010). Young Heterosexual Men's Use of the Miscommunication Model in Explaining Acquaintance Rape. Sexuality Research \& Social Policy, 7, 45-9.

Hickman, S. E., \& Muehlenhard, C. L. (1999). "By the semi-mystical appearance of a condom": How young women and men communicate sexual consent in heterosexual situations. Journal of Sex Research, 36(3), 258-272.

Humphreys, T. (2007). Perceptions of Sexual Consent: The Impact of Relationship History and Gender. Journal of Sex Research, 44(4), 307-315.

Jones, I, (20I2). A problem of the past? The politics of "relevance" in evidential reform. Contemporary Issues in Law, II(4), 277.

Jozkowski, K. N., \& Peterson, Z. D. (20I3). College students and sexual consent: Unique insights. Journal of Sex Research, 5o(6), 517-523.

Khan, U. (2014). Vicarious Kinks: s/m in the socio-legal imaginary, Toronto: University of Toronto Press.

Kitzinger, C., \& Frith, H. (1999). Just say no? The use of conversation analysis in developing a feminist perspective on sexual refusal. Discourse \& Society, Io(3), 293-316.

Koon-Magnin, S. (20I2). Young Adults' Perceptions of Non-Forcible Sexual Activity: The Effects of Participant Gender, Respondent Gender, and Sexual Act. Sex Roles, 67, 646-658.

Koss, M. P., Abbey, A., Campbell, R., Cook, S; Norris, J., Testa, C., Ullman, S., West, C., \& White, J. (2007). Revising the SES: A collaborative process to improve assessment of sexual aggression and victimization. Psychology of Women Quarterly, 31: 357-370.

Krahé, B., Bieneck, S., \& Scheinberger-Olwig, R. (2007). Adolescents' Sexual Scripts: Schematic Representations of Consensual and Nonconsensual Heterosexual Interactions. Journal of Sex Research, 44(4), 316-327.

LaPlante, M. N., McCormick, N., \& Brannigan, G. G. (1980). Living the sexual script: College students' views of influence in sexual encounters. Journal of Sex Research, I6(4), $338-355$.

Lim, G. Y., \& Roloff, M. E. (1999). Attributing sexual consent. Journal of Applied Communication Research, 27: I-23.

Littleton, H., Tabernik, H., Canales, E. J., \& Backstrom, T. (2009). Risky Situation or Harmless Fun? A Qualitative Examination of College Women's Bad Hook-up and Rape Scripts. Sex Roles, 60, 793-804.

Littleton, H. (20II). Rape Myths and Beyond: A commentary on Edwards and colleagues. Sex Roles, 65, 792-797. 
Masser, B., Lees, K., \& McKimmie, B. M. (2009). Bad woman, bad victim? Disentangling the Effects of Victim Stereotypicality, Gender Stereotypicality and Benevolent Sexism on Acquaintance Rape Victim Blame. Sex Roles, 62, 494-504.

Masters, N. T., Casey, E., Wells, E. A., \& Morrison, D. M. (2013). Sexual Scripts among Young Heterosexually Active Men and Women: Continuity and Change Journal of Sex Research, 50(5), 409-420.

Munro, V. (2005). Concerning Consent: Standards of permissibility in sexual relations. Oxford Journal of Legal Studies, 25(2), 335-352.

Newcombe, P. A., van den Eynde, J., Hafner, D., \& Jolly, L. (2008). Attributions of Responsibility for Rape: Differences Across Familiarity of Situation, Gender, and Acceptance of Rape Myths. Journal of Applied Social Psychology, 38(7), I736-1754.

O’Byrne, M., Rapely, M., \& Hansen, S. (2006). "You couldn't say 'No', could you?” Young men's understandings of sexual refusal. Feminism and Psychology, I6, I33-154.

Panichas, G. E. (2006). Simple rape and the risks of sex. Law and Philosophy, 25, 6r3-66r.

Peterson, Z. D., \& Muehlenhard, C. L. (2007). Conceptualizing the "Wantedness" of Women's Consensual and Nonconsensual Sexual Experiences: Implications for How Women Label Their Experiences with Rape. Journal of Sex Research, 44(I), 72-88.

Reece, H. (2013). Rape Myths: Is Elite Opinion Right and Popular Opinion Wrong? Oxford Journal of Legal Studies, 33(3), 445-473.

Rudman, L. A., Fetterolf, J. C., \& Sanchez, D. T. (2013). What Motivates the Sexual Double Standard? More Support for Male Versus Female Control Theory. Personality \& Social Psychology Bulletin, 39(2), 250-263.

Rumney, P.N.S. (1999). When Rape Isn't Rape: Court of Appeal Sentencing Practice in Cases of Marital and Relationship Rape. Oxford Journal of Legal Studies, 19(2), 243-268.

Russell, B., Oswald, D. L., \& Kraus, S. W. (20II). Evaluations of Sexual Assault: Perceptions of Guilt and Legal Elements for Male and Female Aggressors Using Various Coercive Strategies. Violence and Victims, 26(6), 799-8I5.

Russell, B. L., \& Oswald, D. L. (200I). Strategies and Dispositional Correlates of Sexual Coercion Perpetrated by Women: An Exploratory Investigation. Sex Roles, 45, I03-II6.

Russell, Y. (2013). Thinking sexual difference through the law of rape. Law Critique, 24, $255-275$.

Ryan, K. M. (20II). The Relationship between Rape Myths and Sexual Scripts: The Social Construction of Rape. Sex Roles, 65, 774-782.

Sahl, D. S., \& Keene, J. R. (20I0). The Sexual Double Standard and Gender Differences in Predictors of Perceptions of Adult-Teen Sexual Relationships. Sex Roles, 62, 264-277.

Sakaluk, J. K., Todd, L. M., Milhausen, R., Lachowsky, N. J., \& Undergraduate Research Group in Sexuality (URGiS). (2013). Dominant Heterosexual Sexual Scripts in Emerging Adulthood: Conceptualization and Measurement. Journal of Sex Research, 5I, 5I6-53I.

Schuller, R. A., McKimmie, B. A., Masser, B. M., \& Klippenstine, M. A. (2010). Judgments of sexual assault: The impact of complainant demeanor, gender, and victim stereotypes. New Criminal Law Review, I3(4), 759-780.

Stahl, T., Eek, D., \& Kazemi, A. (20I0). Rape Victim Blaming as System Justification: The Role of Gender and Activation of Complementary Stereotypes. Social Justice Research, 23(4), 239-258. 
Strang, E., Peterson, Z. D., Hill, Y. N., \& Heiman, J. R. (2013). Discrepant Responding across Self-Report Measures of Men's Coercive and Aggressive Sexual Strategies. Journal of Sex Research, 5o(5), 458-469.

Tadros, V. (2006). Rape without consent. Oxford Journal of Legal Studies, 26(3), 515-543.

Temkin, J. (2010). "And always keep a-hold of nurse, for fear of finding something worse": Challenging rape myths in the courtroom. New Criminal Law Review, 13(4), 710-734. Turchik, J. A., Probst, D. R., Irvin, C. R., Chau, M., and Gidycz, C. (20I0). Prediction of Sexual Assault Experiences in College Women Based on Rape Scripts: A Prospective Analysis. Psychology of Violence, $I(\mathrm{~S}), 76-83$.

Vannier, S. A., \& O'Sullivan, L. F. (20II). Communicating Interest in Sex: Verbal and Nonverbal Initiation of Sexual Activity in Young Adults' Romantic Dating Relationships. Archives of Sexual Behaviour, 40(5), 96I-969.

Wallerstein, S. (2009). "A drunken consent is still consent"-or Is It? A Critical Analysis of the Law on a Drunken Consent to Sex Following Bree. Journal of Criminal Law, 73(4), 318-344. 